\title{
Frontiers in Ecology and the Environment
}

\section{Human impacts on multiple ecological networks act synergistically to drive ecosystem collapse}

Alfonso Valiente-Banuet and Miguel Verdú

Front Ecol Environ 2013; doi:10.1890/130002

This article is citable (as shown above) and is released from embargo once it is posted to the

Frontiers e-View site (www.frontiersinecology.org).

Please note: This article was downloaded from Frontiers e-View, a service that publishes fully edited and formatted manuscripts before they appear in print in Frontiers in Ecology and the Environment. Readers are strongly advised to check the final print version in case any changes have been made. 


\title{
Human impacts on multiple ecological networks act synergistically to drive ecosystem collapse
}

\author{
Alfonso Valiente-Banuet ${ }^{1,2^{*}}$ and Miguel Verdú ${ }^{3}$
}

Highly biodiverse ecosystems worldwide are rapidly losing species diversity as a result of human overexploitation of natural resources. However, it is not known whether there is a critical threshold of species loss at which an ecosystem fails to recover, leading to its collapse. By combining multiple ecological networks (including facilitation, pollination, and seed dispersal) into a realistic scenario, we document how an ecosystem may collapse through synergistic disruptions to those networks. Although the interdependence of different ecological networks is indicative of ecosystem fragility and low resilience, our findings may improve environmental remediation efforts, thereby helping to bridge the gap between the disciplines of ecology and conservation biology.

Front Ecol Environ 2013; doi:10.1890/130002

$\mathrm{T}$ he identification of thresholds that could potentially lead to ecosystem collapse is a central concern for conservation biologists. Unprecedented anthropogenic changes are making ecosystems more vulnerable to catastrophic shifts as a result of the loss of species and their associated ecosystem services (Cardinale et al. 2012). The gap between theory on ecosystem collapse and practical responses (eg sustainable management practices) is so wide that researchers can neither predict which species are most at risk from human activities nor determine the presence of critical collapse-related thresholds. Network theory is a useful tool for simulating co-extinction cascades following the removal of particular species (Dunne and Williams 2009); these simulations have typically been performed as part of theoretical scenarios, as opposed to more realistic, human-driven extinction scenarios.

Arid ecosystems can abruptly shift to desert conditions as external conditions change (Solé 2007). A dramatic reduction in plant productivity is the first reaction of the ecosystem to external perturbations, but researchers tend to pay little attention to how these changes reverberate in other ecological networks to explain sudden transitions from green to desert landscapes. Thresholds leading to critical transitions are often crossed when local human impacts are amplified by the synergistic interactions of different ecological processes or through feedback loops (Barnosky et al. 2012). The local extinction of species may produce drastic co-extinctions of their mutualistic

${ }^{1}$ Departamento de Ecología de la Biodiversidad, Instituto de Ecología, Universidad Nacional Autónoma de México, México DF, México * (avalient@ecologia.unam.mx); ${ }^{2}$ Centro de Ciencias de la Complejidad, Ciudad Universitaria, Universidad Nacional Autónoma de México, México DF, México; ${ }^{3}$ Centro de Investigaciones sobre Desertificación (CSIC-UV-GV), Carretera Moncada-Náquera, Valencia, Spain partners through feedback processes that may cascade across other ecological networks. These feedback processes across multiple networks have rarely, if ever, been considered in co-extinction simulations; instead, simulations have been framed within a unidirectional scenario in which the extinction of a species in a first guild (eg plants) leads to the co-extinction of its mutualists in other guilds (eg pollinators; Figure 1a) without further feedback effects. In contrast, by including feedback loops in mutualistic networks, it is assumed that extinctions in one guild may produce co-extinctions in other guilds, which in turn may cause additional co-extinctions in the first guild, and so on (Figure 1b).

Here, we develop a new perspective under a more realistic scenario, one that allows the integration of a plethora of ecological interactions to occur synergistically. We quantitatively document how human effects in one network may, through feedback loops, impact concomitant networks of interactions to produce co-extinction cascades and eventually lead to ecosystem collapse. We focus on concomitant facilitation (an interaction describing how nurse plants facilitate the regeneration of other plant species), pollination, and seed dispersal networks that occur in one of the most biodiverse areas of the world, Mexico's Tehuacán-Cuicatlán Biosphere Reserve.

\section{The sociological and ecological scenario}

The Tehuacán-Cuicatlán Biosphere Reserve is located $250 \mathrm{~km}$ southeast of Mexico City, in one of the most biologically rich, semi-arid regions of the Western Hemisphere; this area is characterized by a high degree of endemism among different taxonomic groups, such as columnar cacti and Agave species (Dávila et al. 2002). This region also features a rich cultural history and is 


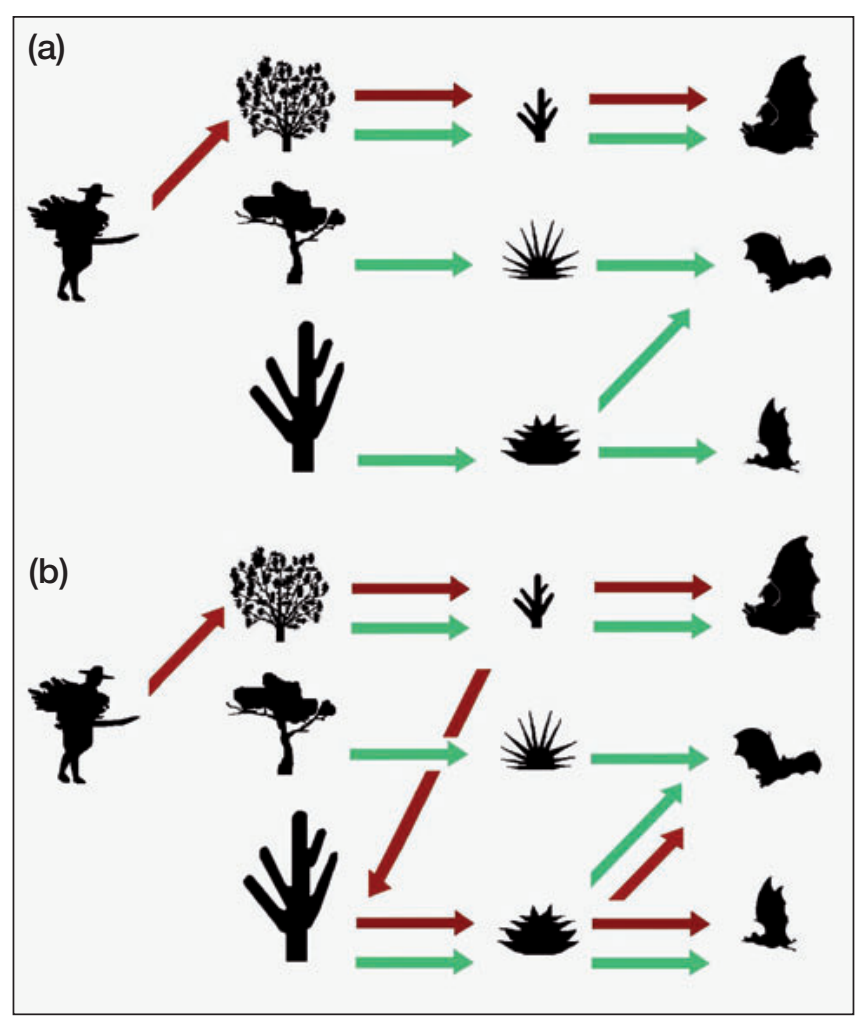

Figure 1. Co-extinction cascades in ecological (eg facilitation and pollination) networks under (a) unidirectional and (b) cyclical scenarios. Green arrows indicate positive interactions (ie facilitation between nurse species and facilitated species and pollination of columnar cacti and agaves by bats). Red arrows indicate extinction cascades as a result of human impacts on a single nurse species. Co-extinction is produced when a facilitated plant species loses its nurse species or when a pollinator loses the plants from which it feeds. Co-extinction cascades in the facilitation network are magnified under the cyclical scenario, ultimately collapsing the entire concomitant pollination network (b).

considered to be the cradle of the Mesoamerican civilization (Byers 1967). We focused on Los Reyes Metzontla, a town with a subsistence economy largely tied to ceramic pottery production. Ceramic production in Los Reyes Metzontla follows the same production procedures as were used 2000 years ago, requiring a few plant species as fuel to fire the pottery outdoors. Production has increased since the 1960 s, when the pottery was seen as a way to alleviate poverty; however, this has led to an increasing demand for large volumes of wood for fuel and the overexploitation of some tree species (De la Vega 2006). Annual wood extraction used for firing ceramics amounts to $1.66 \times 10^{6} \mathrm{~kg}$ (640 families each consuming approximately $50 \mathrm{~kg}$ of wood per week over the course of one year; McAuliffe et al. 2001). Increasing commercial pressures and poverty have intensified the overexploitation of different species that are crucial in the networks of ecological interactions. This overexploitation has created large degraded areas containing very few species; of particular concern is that this critical state has continued for over 20 years with no evidence of ecosystem recovery after abandonment (Figure 2). Degraded areas are intermixed with conserved patches of scrublands with much higher biodiversity and harboring approximately 100 plant species. We identified the factors underlying overexploitation as wood harvesting for fuel and the use of Agave potatorum and Agave marmorata to produce mezcal, an alcoholic beverage for which international demand has increased dramatically (Martínez-Gándara 2008).

Most plant species in these communities recruit only through facilitation, beneath the canopies of other species (ie nurse species; Verdú et al. 2010). Many of the species exploited for firewood are nurse species that facilitate many species in the network (ie acting as hubs in the facilitation networks). Similarly, most of the species harvested for mezcal are facilitated species providing nectar and fruits for animals (ie acting as hubs in pollination and seed dispersal networks) (Flores 2005; Estrella 2007; Verdú et al. 2010). We hypothesize that the intensified anthropogenic impacts affecting these ecological networks over the past several decades have triggered coextinction cascades, thereby pushing this arid ecosystem toward a critical state without the possibility of recovery.

\section{Materials and methods}

We first collected field data to assemble the ecological interaction networks with information from well-preserved areas of the Tehuacán-Cuicatlán Valley. We linked the ecological networks - starting with facilitation, following with pollination, and ending with seed dispersal - into a series, based on the hypothesis that human-induced extinction of a nurse plant will lead to co-extinction of its facilitated species, especially columnar cacti, which are primarily pollinated by bats. We then simulated co-extinction cascades across these ecological networks by removing from the facilitation network the plant species that were being overexploited by local inhabitants (Casas 2001). Finally, we tested simulation accuracy by comparing the species predicted to become extinct or to survive with the species present or absent in the disturbed areas where human overexploitation occurs. We also experimentally tested whether the co-extinction cascade will lead to a shortage of bat dispersers, thereby inhibiting the arrival of new seeds to the ecosystem.

The facilitation network was constructed as a matrix, linking the number of individuals of each facilitated species associated with each nurse species (see WebPanel 1 for details). For the pollination and seed dispersal networks, we focused on the relationships established between bats and columnar cacti and agaves, the most abundant plant species in the area, whose flowers are strongly associated with pollination by animals and whose fleshy fruits (cacti only) are dispersed by animals. Consequently, we worked with only a subset of species within the entire pollination and dispersal networks. The pollination network was based on experimental data and focal observations (WebPanel 1) and, for phenological 

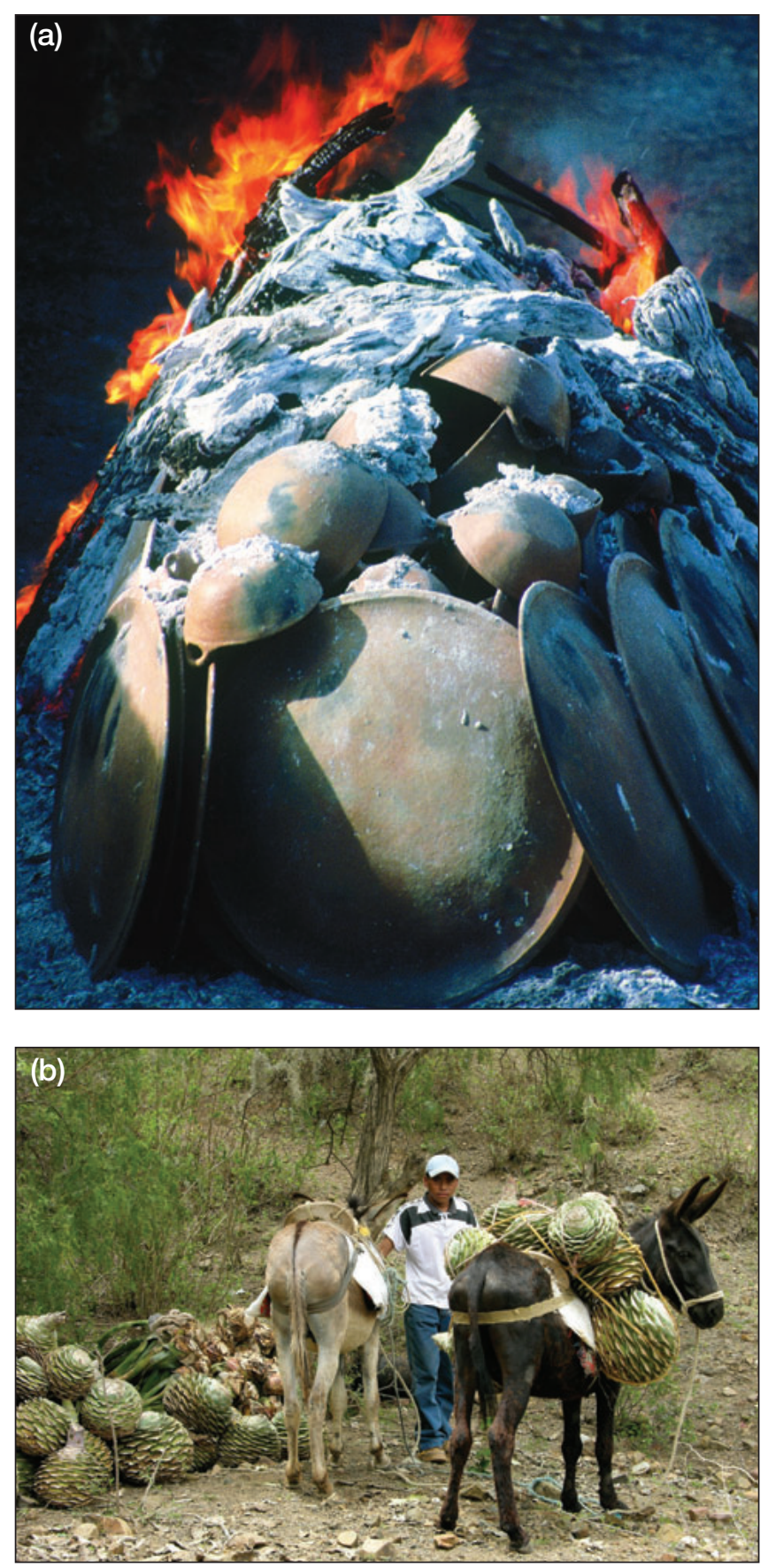

reasons, was split into two stages: (1) early (February to April), the most nectar-limited time of the year, when most Agave species are in bloom and when columnar cacti start blooming, and (2) late (May to January), when most columnar cacti and A potatorum are also blooming. Likewise, the seed dispersal network was constructed on the basis of seed identification from frugivore feces, including that obtained from bat refugia (WebPanel 1).

Co-extinction simulations based on qualitative data (presence/absence of interactions) remove a given species from the network only when all of its mutualists have disappeared. However, this protocol may underestimate coextinction rates because a reduction in mutualist abundances, below a critical threshold but before actual
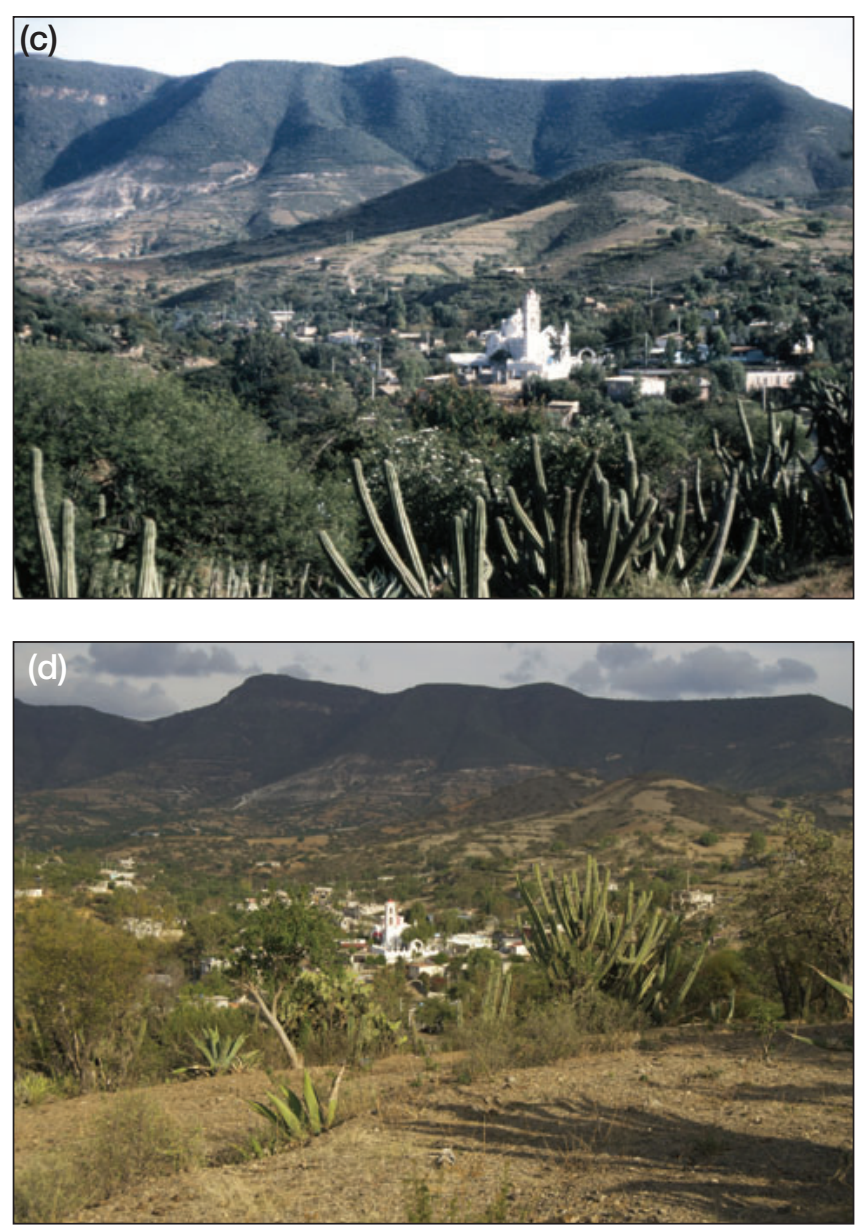

Figure 2. Plant exploitation by humans for (a) firewood and (b) mezcal production has pushed the ecosystem toward a degraded state where natural regeneration has been compromised. The lack of plant regeneration results in a critical state maintained for more than 20 years after the abandonment of local exploitation practices. Photographs in (c) and (d) were taken in 1991 and 2012 , respectively.

extinction, may be enough to drive co-extinction (Amarasekare 2004). To explore such thresholds, we used quantitatively measured facilitation networks, which allowed the incorporation of metrics reflecting the dependence of facilitated plant species on nurse species; we could then relate this dependence not only to species abundance but also to the specificity of each particular interaction (Verdú et al. 2010). Thus, the consequence of removing a particular species from the network is most important in analyzing mutualists, which are more strongly dependent on it. To simulate a quantitative scenario in which nurse species extinction produces coextinction of their facilitated species, we calculated the dependence $d_{i j}$ of facilitated plant species $i$ on nurse species $j$ (ie the proportion of the total number of individuals of species $i$ recruiting under nurse species $j$; Bascompte et al. 2006). Because $d_{i j}$ measures the importance of nurse species for each facilitated plant species, we considered a facilitated plant species to become coextinct when the sum of its dependencies across nurse 


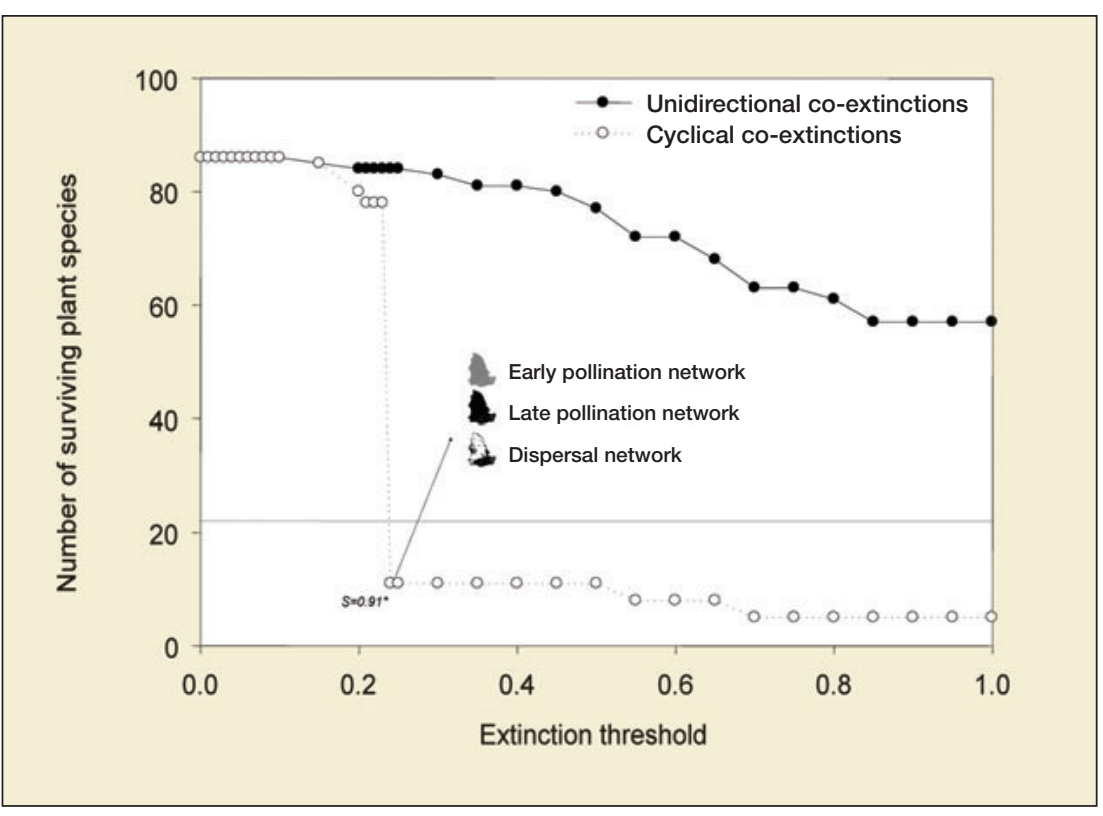

Figure 3. Co-extinction simulations in facilitation networks under unidirectional and cyclical scenarios at different extinction thresholds. Thresholds indicate the dependence $\mathrm{d}_{\mathrm{ij}}$ of facilitated plant species $\mathrm{i}$ on nurse species $\mathrm{j}$ (proportion of individuals of a species recruiting under a given nurse species). A facilitated plant species becomes co-extinct when the sum of its dependencies across nurse species $\left(\mathrm{d}_{\mathrm{i}}\right)$ was lower than a particular threshold. The horizontal line shows the number of species surviving in the degraded community. The maximum similarity between predicted and observed extinctions occurred when the threshold was equal to 0.24 in the cyclical scenario (Sorensen index $S=0.91$ ). The asterisk denotes that all thresholds $\geq 0.24$ in the cyclical scenario revealed a significant association between observed and predicted extinctions ( $\chi^{2}$ test). The arrow indicates collapses in pollination and dispersal networks.

species $\left(d_{i}\right)$ was lower than a particular threshold. We also considered open ground (as possible sites of plant recruitment) as an element in the network. Several extinction thresholds ranging from 0 to 1 were simulated. A threshold equaling 0 indicates that a facilitated species is removed from the network only when the sum of its dependencies is zero (that is, when all of its nurse species have disappeared). When the threshold is 0.5 , a facilitated species is removed from the network when the sum of its dependencies is less than 0.5. This threshold can be achieved by removing a very important nurse species for the facilitated species or by removing several less important nurse species.

In addition to traditional unidirectional co-extinction scenarios, we performed simulations allowing feedback loops, which more realistically depict the cyclical dynamics governing facilitation processes in our study system (Verdú et al. 2009). Such cyclical dynamics occur because species $x$ acts as a nurse for the recruitment of species $y$, species $y$ acts as a nurse for species $z$, and species $z$ acts as a nurse for species $x$ (see Figure 1 in Verdú et al. 2009). We considered the concomitant pollination and seed dispersal networks to have collapsed when all the plant species supplying food to the bats went co-extinct with their nurse species.
To verify the accuracy of the simulations' predictions, we compared predicted and observed values through chi-square tests of association. We constructed a $2 \times 2$ contingency table crossing the number of surviving and extinct species obtained from the simulations with the present and absent species in the human-disturbed (overexploited) area. In addition, we quantified the similarity between the species' lists of simulated and observed extinctions through the Sorensen index of similarity. A seed limitation experiment - sowing five replicates of 20 seeds each for the batdispersed cacti Neobuxbaumia tetetzo, Neobuxbaumia macrocephala, and Mitrocereus fulviceps under different nurse species - was performed to test whether columnar cacti fail to establish in the degraded areas because of an absence of protected sites.

\section{Results}

The facilitation network in the non-disturbed adjacent area is populated by 50 nurse species and 90 facilitated species. Our co-extinction simulations triggered by the removal of only $16 \%$ of species show that extinctions are dramatically accelerated under a cyclical co-extinction scenario (Figure 3; WebFigure 2). A distinct threshold appears at $d_{i j}=0.24$, indicating that the ecosystem collapses when the nurse species habitat availability is reduced to below $76 \%$ of its original extent. In contrast, collapse did not occur at any extinction threshold under the unidirectional scenario, which tends to underestimate the number of extinctions in the conserved vegetation and only approaches the extinction level empirically measured in the degraded system when using high extinction thresholds. In contrast, the cyclical scenario rapidly approaches the empirically measured extinction level and stabilizes across different extinction thresholds.

The similarity between the observed and predicted species extinctions under the directional scenario was low across all thresholds (Sorensen index ranging from 0.24 to 0.52 ), and thus simulated changes in species composition were not significantly associated with observed changes $\left(\chi^{2}\right.$ ranging from 0 to 1.04 ; all $P$ values $>0.3$; Figure 3). However, under the cyclical scenario, the similarity between predicted and observed species extinctions was very high, at extinction thresholds $>0.24$ (Sorensen index ranging from 0.88 to 0.91 ). Accordingly, simulated changes in species composition at these thresholds were significantly associated with observed changes $\left(\chi^{2}\right.$ ranging from 5.8 to 17.9 ; all $P$ values $<0.05$; Figure 3$)$. Our 
simulations correctly predicted 75 out of 77 extinctions and 8 out of 22 survivals observed in the degraded area (scientific names in green and black text in WebFigure 2 ) and only failed to predict the extinction of two species (scientific names in blue text in WebFigure 2). The model also predicted 14 extinctions that were not observed in the degraded area (scientific names in red text in WebFigure 2). These incorrectly predicted extinctions were the result of the presence of some species that (1) resprout (eg Acacia constricta), (2) are managed in situ for agricultural and/or domestication purposes (eg Lippia graveolens, Stenocereus stellatus), or (3) are able to recolonize through bird-mediated (eg Cordia curassavica, Opuntia spp, Lantana spp) or abiotic (eg Ipomoea arborescens, Viguiera grammatoglossa, Aeschynomene compacta, Ayenia fruticosa, Cardiospermum halicacabum, Croton ciliato-glanduliferus) dispersal. Some of these mismatches are clearly a consequence of working with restricted pollination and dispersal networks. Future research including the entire pollination and dispersal networks will probably solve such mismatches.

Notably, none of the incorrectly predicted extinctions due to strong recolonization ability corresponded with bat-dispersed plants (eg columnar cacti), and our simulations correctly predicted their extinction (WebFigure 2). Recruitment of bat-dispersed plants in the degraded area is completely absent despite the presence of protected sites provided by nurse species in the community and the opportunity for seeds to potentially establish below them, as demonstrated by the seed-sowing experiments (WebFigure 1). Bat-dispersed seeds are thus not arriving in the degraded area because of dispersal limitation, a result that is consistent with the impact that co-extinctions in the facilitation network have in the concomitant pollination and dispersal networks (Figure 3; WebFigure 2). Without the nectar and pollen of agaves and columnar cacti, nectar-feeding bats must migrate out of this part of the valley and consequently are no longer available as pollinators and seed dispersers. Pollination and dispersal services performed by bats may abruptly disappear when a critical abundance threshold is crossed (McConkey and Drake 2006). The feeding behavior of the nectar-feeding bat Leptonycteris curasoae - the most important pollinator of Agave and columnar cacti - is highly affected by floral availability (Estrella 2007). Thus, visitation rates of the nectar-feeding bat to A potatorum, the most important species for mezcal production, is highest in localities with the highest overall floral density. At medium floral densities, diurnal pollinators were inefficient, whereas at the lowest floral density pollination was totally absent (Estrella 2007). Our simulations predicted this impact in the concomitant networks but only in the cyclical dynamic scenario (Figure 3), highlighting the importance of including feedback loops to recreate complex interactions and the potential for thresholds of ecosystem collapse.

\section{Conclusions}

Anthropogenic exploitation of particular plant species may trigger a vortex of co-extinctions, ultimately leading to ecosystem collapse; in our example, natural regeneration has been unable to counteract this degraded state for more than 20 years. The presence of complex interdependent networks of species and their interactions emphasizes the inherent fragility of ecosystems and their reduced capacity for resilience. In other words, the disruption of the multi-network structure contributes greatly to ecosystem collapse, consequently affecting ecosystem services. Furthermore, species loss reduces human wellbeing not only at the local scale but also potentially at the regional scale, given that wood used for pottery production and for cooking is obtained from nearby localities by people from other municipalities. At the same time, local overexploitation of plants may prompt migration of other network interactors (eg seed pollinators and dispersers) to distant parts of the valley.

Integrating different types of interactions under a unified framework is crucial to understanding ecological community dynamics (Fontaine et al. 2011). The current challenge is to apply the knowledge from this multi-network structure to assess the sustainability of the resource exploitation practices and to counteract ecosystem collapse. The identification and protection of species that act as hubs in ecological networks is an urgent task. For example, the protection of Agave and columnar cacti species is key for maintaining nectarfeeding bats, the plants' most effective pollinators and dispersers. With growing global demand for mezcal leading to wild-plant overexploitation and to potential expansion of commercial monoculture clone plantations (Vargas-Ponce et al. 2009), this scenario could not only devastate nectar-feeding bat populations in the region but also promote soil erosion, chemical pollution, and displacement of traditional food crops and traditional Agave landraces used in the production of mezcal (Zizumbo-Villarreal et al. 2012).

The results presented here help to fill the gap between ecological theory and conservation practice, demonstrating the necessity of removing the traditional communication barriers among ecologists, social scientists, and economists. We argue that such collaboration is crucial in the development of viable and sustainable land-use practices within biodiverse areas, to maintain biodiversity while alleviating human poverty.

\section{Acknowledgements}

We thank RM Callaway, C Fontaine, and A Montesinos for comments and discussions, as well as C Silva for assistance in the field and laboratory. Funding was provided by PAPIIT-DGAPA, UNAM (IN-202811-3) and CYTED (Acción 409AC0369). AV-B and MV conceived the study, analyzed the data, and wrote the manuscript. 


\section{References}

Amarasekare P. 2004. Spatial dynamics of mutualistic interactions. J Anim Ecol 73: 128-42.

Barnosky AD, Hadly EA, Bascompte J, et al. 2012. Approaching a state-shift in Earth's biosphere. Nature 486: 52-58.

Bascompte J, Jordano P, and Olesen JM. 2006. Asymmetric coevolutionary networks facilitate biodiversity maintenance. Science 312: 431-33.

Byers DS (Ed). 1967. The prehistory of the Tehuacan Valley: environment and subsistence. Austin, TX: University of Texas Press.

Cardinale BJ, Duffy JE, Gonzalez A, et al. 2012. Biodiversity loss and its impact on humanity. Nature 486: 59-67.

Casas A, Valiente-Banuet A, Viveros JL, et al. 2001. Plant resources of the Tehuacán Valley, Mexico. Econ Bot 55: 129-66.

Dávila P, Arizmendi MC, Valiente-Banuet A, et al. 2002. Biological diversity in the Tehuacán-Cuicatlán Valley. Biodivers Conserv 11: 421-42.

De la Vega DS. 2006. La alfarería en los Reyes Metzontla: pasado, presente y futuro. Mexico City, Mexico: INAH.

Dunne JA and Williams RJ. 2009. Cascading extinctions and community collapse in model food webs. Phil Trans R Soc Lond B 364: 1711-23.

Estrella RJP. 2007. Efecto de la explotación humana en la biología de la polinización de Agave salmiana y Agave potatorum en el Valle de Tehuacán-Cuicatlán (MSc thesis). Mexico City, Mexico: Universidad Nacional Autónoma de Mexico.

Flores A. 2005. Competencia por polinización en dos especies de agaves con floración traslapada del Valle de Tehuacán, México (MSc thesis). Mexico City, Mexico: Universidad Nacional
Autónoma de Mexico.

Fontaine C, Guimaraes Jr PR, Kéfi S, et al. 2011. The ecological and evolutionary implications of merging different types of networks. Ecol Lett 14: 1170-81.

Martínez-Gándara A. 2008. Tequila, mezcal y cerveza: de México para el mundo. Agric Soc Des 2: 143-50.

McAuliffe JR, Sundt PC, Valiente-Banuet A, et al. 2001. PreColumbian soil erosion, persistent ecological changes, and collapse of a subsistence agricultural economy in the semi-arid Tehuacán Valley, Mexico's "Cradle of Maize”. J Arid Env 47: 47-75.

McConkey KR and Drake DR. 2006. Flying foxes cease to function as seed dispersers long before they become rare. Ecology 87: 271-76.

Solé R. 2007. Ecology: scaling laws in the drier. Nature 449: 151-53.

Vargas-Ponce O, Zizumbo-Villarreal D, Martínez-Castillo J, et al. 2009. Diversity and structure of landraces of Agave grown for spirits under traditional agriculture: a comparison with wild populations of A angustifolia (Agavaceae) and commercial plantations of A tequilana. Am J Bot 96: 448-57.

Verdú M, Rey PJ, Alcántara JM, et al. 2009. Phylogenetic signatures of facilitation and competition in successional communities. J Ecol 97: 1171-80.

Verdú M, Jordano P, and Valiente-Banuet A. 2010. The phylogenetic structure of plant facilitation networks changes with competition. J Ecol 98: 1454-61.

Zizumbo-Villarreal D, Vargas-Ponce O, Rosales-Adame JJ, et al. 2012. Sustainability of the traditional management of Agave genetic resources in the elaboration of mezcal and tequila spirits in western Mexico. Genet Resour Crop Evol 60: 33-47. 


\section{WebPanel 1. Methods}

\section{Construction of ecological networks}

\section{Facilitation networks}

We constructed facilitation networks to record facilitative interactions by counting the number of seedlings and saplings $(<30 \mathrm{~cm}$ high) growing beneath nurse species and in open spaces along four $1000-\mathrm{m}^{2}$ transects. Facilitated species were those recruiting under vegetation (nurse species). Experimental evidence in the study area clearly indicates that these spatial patterns of association between juvenile and larger plants are due to facilitation and not to mere spatial coincidence (ValienteBanuet and Ezcurra 1991; Castillo and Valiente-Banuet 2010; Castillo et al. 2010). Valiente-Banuet and Ezcurra (1991), Valiente-Banuet and Verdú $(2007,2008)$, and Castillo et al. (20I0) provide detailed descriptions of sampling methods and the mechanisms underlying facilitation in the study area; these studies experimentally determined that facilitative interactions are species-specific and that this specificity is linked to evolutionary relationships among species (Verdú et al. 20I0).

\section{Pollination networks}

For pollination networks, we focused on the relationships between bats and columnar cacti and agaves, the most abundant plant species in the area; densities of columnar cacti and of Agave species can reach more than 1000 and almost 100 individuals per hectare, respectively. Because two clearly differentiated flowering seasons occur in the Tehuacán-Cuicatlán Valley, we created (I) an early pollination network (February to April), the most nectar-limited time of the year, when most Agave species (ie Agave peacockii, Agave marmorata, and Agave salmiana) bloom massively (Rojas-Martínez et al. 1999; Ornelas et al. 2002) and when columnar cacti start blooming; and (2) a late pollination network (May to January), when most columnar cacti and Agave potatorum bloom extensively (Flores 2005; Estrella 2007).

The pollination networks were constructed by conducting pollination studies in which we assessed the most effective pollinators of the columnar cacti Neobuxbaumia tetetzo, Neobuxbaumia macrocephala, Mitrocereus fulviceps, and Cephalocereus columna-trajani (Valiente-Banuet et al. 1996, 1997) and of $A$ potatorum, $A$ marmorata, $A$ peacockii, and $A$ salmiana (Flores 2005; Estrella 2007). Flower visitor information was obtained based on (I) direct observations during day and night and $(2)$ the use of five mist nets $(20 \mathrm{~m} \times 3 \mathrm{~m})$ to capture animal visitors during a 5- to 8-day period. For all captured animals, pollen preparations were made by rubbing a cube of fuchsinstained jelly over the animal's body. The cube was then placed on a microslide, melted, and covered with a coverslip for microscopic examination. Pollen presence and direct observations were regarded as proof of flower visitation. Because bats' pollen loads constituted pollen from columnar cacti and Agave species almost exclusively, we restricted the pollination network to these plant species.

For each cactus and Agave species, we measured visitor effectiveness by marking and bagging with mosquito nets a variable number of flower buds from a total of at least 30 plants. Ten to 30 flower buds were then each assigned to one of the following treatments:

(I) Non-manipulated self-pollination: flower buds were bagged and monitored until flowers aborted or set fruit.

(2) Nocturnal pollination: flower buds were bagged before opening. Upon opening, flowers were exposed to nocturnal floral visitors by bag removal from 24-hour-clock time 20:00 to 05:00 (I hour before sunrise). Afterward, flowers were rebagged and monitored until abortion or fruit production.

(3) Diurnal pollination: flower buds were bagged before opening. Upon opening, flowers were exposed to diurnal floral visitors by removing the bag at 06:00 until flowers closed at 10:30 (for cacti) and during all day until sunset (for Agave species). Afterward, flowers were rebagged and monitored until abortion or fruit production.

(4) Cross-pollination: flower buds were bagged before opening. Upon opening, flowers were hand-pollinated, using pollen obtained from another plant.

(5) Self-pollination: flower buds were bagged before opening. Upon opening, flowers were hand-pollinated, using pollen from the same plant.

(6) Unmanipulated, open-pollinated flowers: flowers were marked and left until abortion or fruit production.

Research indicates that the Agave species and columnar cacti studied here exhibit a high degree of specialization for bat pollination. Columnar cacti cannot produce seeds in the absence of the nectar-feeding bats Leptonycteris curasoae and Choeronycteris mexicana, which have resident populations throughout the year; by comparison, seed production in Agave species relies mostly on L curasoae, C mexicana, and Leptonycteris nivalis. Both Agave and cactus species provide bats with pollen and nectar; cacti also offer seeds for a $\sim 9$-month period.

\section{Seed dispersal networks}

Dispersal networks also focused on the relationships established between columnar cacti and the nectar-feeding bats $L$ curasoae and $C$ mexicana, the most important seed dispersers of columnar cacti in the area (Godínez-Alvarez et al. 2002). At night, these bats may remove around $75 \%$ of the seeds from the plants' fruits.

Seed dispersal networks were constructed for the dominant columnar cacti species inhabiting the study area, based on previous studies for $N$ tetetzo (Godínez-Alvarez et al. 2002). For C columna-trajani, $M$ fulviceps, and $N$ macrocephala, we determined frugivore dispersal by analyzing the presence of intact seeds in feces of animals captured using five mist nets $(20 \mathrm{~m} \times 3 \mathrm{~m})$ as well as seed identification in bat refuges as evidence of seed transport (Rojas and Salinas 2002). Also, for $N$ macrocephala, the contribution of diurnal and nocturnal seed dispersers was sampled by placing 16 seed collectors of $0.25 \mathrm{~m}^{2}$ plastic net squares nailed to the ground under the canopy of eight different plant species and in open space in an area occupied by the species. These observations indicate that nectar-feeding bats disperse most of the seeds of these columnar cacti.

\section{Identification of the overexploited species}

Within the Tehuacán-Cuicatlán Biosphere Reserve, Los Reyes Metzontla ( $18^{\circ} 12^{\prime} 00^{\prime \prime}$ to $18^{\circ} 15^{\prime} 30^{\prime \prime} \mathrm{N}$ latitude; $97^{\circ} 27^{\prime} 00^{\prime \prime}$ to $97^{\circ} 32^{\prime} 30^{\prime \prime} \mathrm{W}$ longitude) is the location where plant overexploitation (for fuel) occurs. At an average altitude of $1800 \mathrm{~m}$ above sea level, the Los Reyes Metzontla territory is 3648 ha and is characterized by an annual mean temperature of $21^{\circ} \mathrm{C}$ and an annual mean precipitation of $400 \mathrm{~mm}$ (Valiente-Banuet et al. 


\section{WebPanel 1. Methods - continued}

2000). The town has 983 inhabitants who are identified as part of the Popoloca ethnic group.Vegetation is classified as a xerophytic scrubland characterized by the dominance of small trees such as Prosopis laevigata and Ipomoea arborescens; shrubs and succulent species such as $N$ tetetzo, $N$ macrocephala, $M$ fulviceps, Stenocereus stellatus; and several Agave species (ValienteBanuet et al. 2000). As a result of firewood gathering and agricultural activities, most of the vegetation has been greatly modified.

Information about which plant species were overexploited by local inhabitants was obtained from Casas et al. (200I) and through direct interviews during either pottery firing ( 15 interviews) or wood collection in the field ( 5 interviews). In each interview, the plant species preferred for fuel was recorded, in addition to how the wood was used to fire the ceramics.

To quantify the impact of plant overexploitation on the ecosystem, we recorded the list of plant species surviving in the degraded areas by means of four $50 \mathrm{~m} \times 10 \mathrm{~m}$ transects. The species composition was obtained after pooling the information obtained in the four transects.

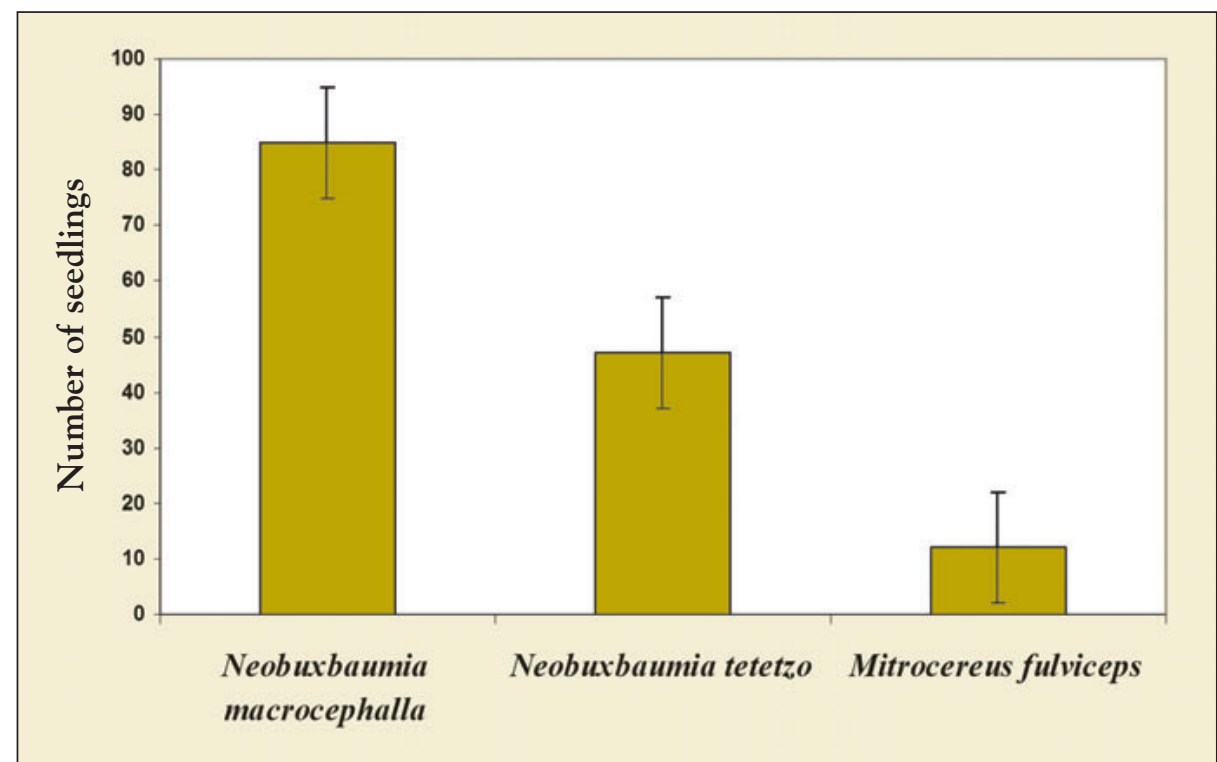

WebFigure 1. Seed-sowing experiments reveal that regeneration in degraded areas is not limited by the availability of safe sites. Data indicate the number of seedlings (mean \pm standard error) of the columnar cacti Neobuxbaumia tetetzo, Neobuxbaumia macrocephala, and Mitrocereus fulviceps established beneath the canopies of four nurse species: Acacia constricta, Cordia curassavica, Prosopis laevigata, and Ipomoea arborescens. Germination rates were significantly different from zero in all species. 


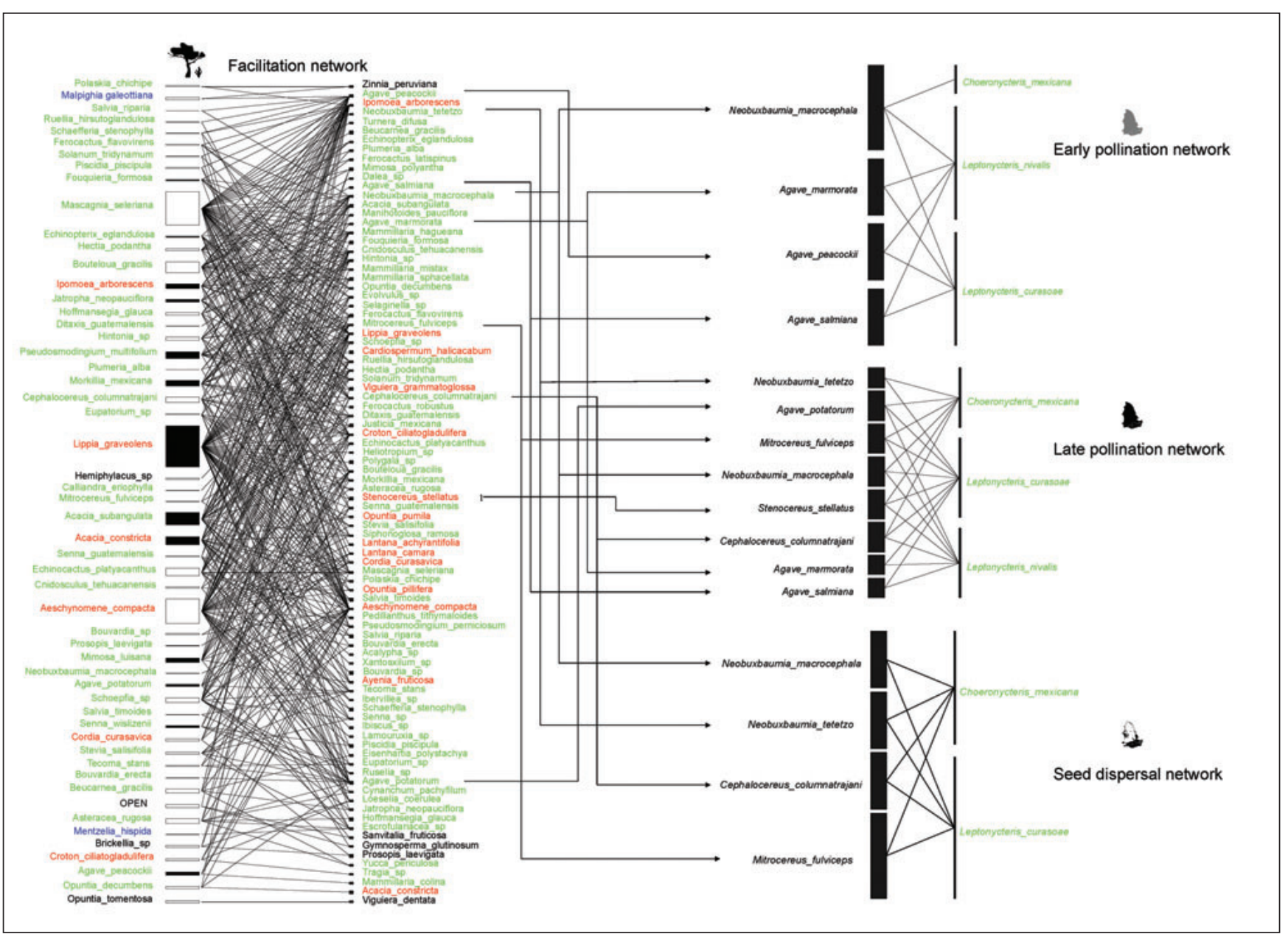

WebFigure 2. Co-extinction cascades produced by the overexploitation of a few nurse species in the facilitation network propagate toward pollination and seed dispersal networks. The quantitative facilitation network in the conserved vegetation connects nurse species (left) with facilitated species (right). Open ground was also considered as a site for recruitment. The size of each rectangle is proportional to the number of interactions. Black rectangles indicate the overexploited nurse species. Scientific names in green text indicate species in which extinction was predicted and observed; in black text, that extinction was neither predicted nor observed; in blue text, that extinction was observed but not predicted; and in red text, that extinction was predicted but not observed. Stenocereus stellatus extinction would have occurred in the degraded community but the species is artificially maintained. 


\section{WebReferences}

Casas A, Valiente-Banuet A, Viveros JL, et al. 2001. Plant resources of the Tehuacán Valley, Mexico. Econ Bot 55: 129-66.

Castillo LJP and Valiente-Banuet A. 2010. Species-specificity of nurse plants for the establishment, survivorship and growth of a columnar cactus. Am J Bot 97: 1289-95.

Castillo JP, Verdú M, and Valiente-Banuet A. 2010. Neighborhood phylodiversity affects plant performance. Ecology 91: 3656-63.

Estrella RJP. 2007. Efecto de la explotación humana en la biología de la polinización de Agave salmiana y Agave potatorum en el Valle de Tehuacán-Cuicatlán (MSc thesis). Mexico City, Mexico: Universidad Nacional Autónoma de Mexico.

Flores A. 2005. Competencia por polinización en dos especies de agave con floración traslapada del Valle de Tehucán, México. (MSc thesis). Mexico City, Mexico: Universidad Nacional Autónoma de Mexico.

Godínez-Alvarez H, Valiente-Banuet A, and Rojas-Martínez A. 2002. The role of seed dispersers in the population dynamics of the columnar cactus Neobuxbaumia tetetzo. Ecology 83: 2617-29.

Ornelas JFM, Ordano M, Hernández A, et al. 2002. Nectar oasis produced by Agave marmorata Roezl (Agavaceae) lead to spatial and temporal segregation among nectarivores in the Tehuacán Valley, México. J Arid Env 52: 37-51.

Rojas-Martínez A, Valiente-Banuet A, Arizmendi MC, et al. 1999. Seasonal permanence of the nectar-feeding bat Leptonycteris curasoae in North America: does a generalized migration pattern really exist? J Biogeogr 26: 1065-78.

Rojas MA and Salinas M. 2002. Frutos de cactáceas columnares consumidas por el murciélago Leptonycteris curasoae en el Valle de Tehuacán, México. Rev Inv Univ Simón Bolivar 1: 21-30.

Valiente-Banuet A and Ezcurra E. 1991. Shade as a cause of the association between the cactus Neobuxbaumia tetetzo and the nurse plant Mimosa luisana in the Tehuacan Valley, Mexico. J Ecol 79: 961-71.

Valiente-Banuet A and Verdú M. 2007. Assembly through facilitation can increase the phylogenetic diversity of plant communities. Ecol Lett 10: 1029-36.

Valiente-Banuet A and Verdú M. 2008. Temporal shifts from facilitation to competition occur between closely related taxa. J Ecol 96: 489-94.

Valiente-Banuet A, Arizmendi MC, Rojas A, et al. 1996. Ecological relationships between columnar cacti and nectar feeding bats in Mexico. J Trop Ecol 12: 103-19.

Valiente-Banuet A, Rojas-Martínez A, Arizmendi MC, et al. 1997. Pollination biology of two columnar cacti (Neobuxbaumia mezcalaensis and Neobuxbaumia macrocephala) in the Tehuacan Valley, Mexico. Amer J Bot 84: 452-55.

Valiente-Banuet A, Casas A, Alcántara A, et al. 2000. La vegetación del Valle de Tehuacán-Cuicatlán. Bol Soc Bot Méx 67: 25-74.

Verdú M, Jordano P, and Valiente-Banuet A. 2010. The phylogenetic structure of plant facilitation networks changes with competition. J Ecol 98: 1454-61. 